\title{
Physical Activity Among Unimas Undergraduates
}

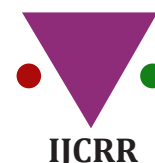

Section: Healthcare

ISI Impact Factor

(2019-20): 1.628

IC Value (2019): 90.81

$\operatorname{SJIF}(2020)=7.893$

(c) (i) (3)

Copyright@IJCRR

\section{Jeffery Anak Stephen ${ }^{1}$, Rafidah Binti Elias ${ }^{2}$, Beatrice Reen Anak Gilbert ${ }^{3}$, Nurul Adilah Binti Mohamed Farid ${ }^{3}$, Desmond Tong Ming Han ${ }^{3}$, Sarah Prosper Anak Atang ${ }^{3}$}

\author{
'Department of Community Medicine and Public Health, Faculty of Medicine and Health Science, University Malaysia Sarawak, Kota Samara- \\ han, Malaysia; '2Department of Family Medicine, Faculty of Medicine and Health Science, University Malaysia Sarawak, Kota Samarahan, \\ Malaysia; ${ }^{3}$ Faculty of Medicine and Health Science, University Malaysia Sarawak, Kota Samarahan, Malaysia.
}

\section{ABSTRACT}

Background: A significant decline in physical activity is seen among young adults during the transition into adulthood.

Objective: This study aims to explore the degree of physical activity among undergraduate students in University Malaysia Sarawak (UNIMAS) and its relationship with five predictors for behavioural change related to participation in physical activity, derived from Health Promotion Model.

Methods: This cross-sectional study was conducted among 440 undergraduate students through multistage random sampling using self-administered questionnaire consists of Global Physical Activity Questionnaire (GPAQ), Exercise Benefit/Barrier Scale (EBBS), Self-rated Abilities for Health Practices Scale (SRAHP), Physical Activity Affect Scale (PAAS) and Physical Activity and Social Support Scale (PASSS).

Results: From 409 respondents, $74.1 \%$ was physically active. Mean age of physically active was 21 years old, Year-2 students $(31.3 \%)$ more active than Year-1 (30.8\%) and Year-3 (12\%), and females (48.7\%) than males (25.4\%). Males were three times more prone to participate in physical activity than females $(\mathrm{OR}=3.533)$. Predictors, namely perceived benefit, perceived barrier, and self-rated ability had a significant relationship with the degree of physical activity, in contrast with social influence and activity-related effect.

Conclusion: Majority were physically active. Only self-rated ability likely to predict a student's participation in physical activity.

Key Words: Physical activity, Predictors, Public health, Undergraduate students

\section{INTRODUCTION}

Physical activity denotes the movement of any part of the body that require the utilization of energy. Whereas, physical inactivity is the opposite and any physical activity that does not meet the standard of physical activity as recommended. ${ }^{1-3}$ It is one of the leading factors of mortality globally. ${ }^{4}$ It linked to various chronic diseases (National Health and Morbidity Survey, NHMS) such as ischaemic heart disease, diabetes mellitus, breast cancer, and colon cancer. ${ }^{5}$ Unfortunately, despite knowing the importance of the physical activity to the human body, the World Health Organisation (WHO) reported that more than half of the global population were physically inactive $(60 \%){ }^{6}$ Based on the Malaysia Adults Nutrition Survey and the other two studies in Penang most of the Malaysian adults were physically inactive (85$89 \%) \cdot{ }^{7,8}$
Various studies had found the possible factors that have the potency to affect an individual's participation in physical activity. Often described factors includes gender, family influence the sociocultural status of individuals, and coming of age. ${ }^{9-12}$ A study by Sigmundova et al. had shown a decline in physical activity upon entering university as the young adult transition into the early phase of adulthood. ${ }^{12}$ Given the low prevalence of participation in physical activity among Malaysian adults, there is a need to study and explore predictors of participation in physical activity as well as sociodemographic backgrounds, namely age, gender, ethnicity, including other related factors for better understanding of the problem. ${ }^{13,14}$

Therefore, the objectives of the study were to ascertain the degree of physical activity among undergraduate students in UNIMAS and its relationship with the five predictors that possibly influence their participation in physical activity to

\section{Corresponding Author:}

Jeffery Anak Stephen, Department of Community Medicine and Public Health, Faculty of Medicine and Health Science, University Malaysia Sarawak, Kota Samarahan, Malaysia; Telephone: +6082-267311; Email: sjeffery@unimas.my

ISSN: $2231-2196$ (Print)

Received: 11.10 .2020
ISSN: 0975-5241 (Online)

Revised: 08.11 .2020
Accepted: 10.12 .2020
Published: 23.02 .2021 
encompass Health Promotion Model (HPM). It is a public health priority to improve the standard of physical activity among university students, considering how public health professional organizations have designed multiple physical activity recommendations to achieve that goal. ${ }^{5,15}$ It is compelling to find out the factors that would affect the participation of youth in physical activity. It will also benefit the authorities in terms of providing useful information for the improvement of the intervention that aims at promoting physical activity among youth. ${ }^{7,11}$

\section{MATERIALS AND METHODS}

\section{Study design}

This study was a cross-sectional study. A total of 440 undergraduate students in UNIMAS were selected through a multistage random sampling method. The sample size was calculated using OpenEpi application using the calculation of sample size for proportion study, whereby a total of 13 517 undergraduate students were used as a total study population and $40 \%$ were used as a hypothesized frequency of physically active adult taken from the previous study by Cai Lian et al. in 2016. The calculated sample size with $95 \%$ confidence interval was 360 . With the addition of $20 \%$ nonresponse rate, the total calculated sample size was 432, rounded up to 440. The inclusion criteria for this study were Malaysian undergraduate students in UNIMAS who able to understand English or Malay. Whereas, the exclusion criteria were students with disabilities, pregnant, and have chronic diseases. The selected students who fulfilled the criteria and consented voluntarily were enrolled in this study. The study was conducted for ten months, starting from September 2019 until June 2020. The Medical Ethical Committee of UNIMAS had approved the study (Reference number: UNIMAS/ NC-21.02/03-02 Jld.4 (14)).

\section{Study tool}

The questionnaire used in this study was self-administered. The questionnaire consists of six parts: (A) sociodemographic characteristics, (B) degree of physical activity, (C) perception of benefit and barrier to physical ability, (D) self-rated ability for physical activity, (E) physical activity-related affect, and (F) social influences.

The Global Physical Activity Questionnaire (GPAQ) in English and Malay version (GPAQ-M) ${ }^{22}$ were used to measure the degree of physical activity. It had a significant correlation with the International Physical Activity Questionnaire (IPAQ) that was used to measure the intensity of the physical activity. ${ }^{22}$ The physical activity was categorized into three, namely high, moderate, and low based on the intensity and duration of physical activity and calculated *MET-minute per week.
The perception of benefit and barrier to physical activity was measured using EBBS.$^{20}$ It demonstrated excellent reliability and convergent validity. Internal consistency for all the items in EBBS was excellent; $\alpha=0.894$ for perceived benefits and $\alpha=0.856$ for perceived barriers. The total score for each subdomain was analyzed separately. The higher the total score, the higher an individual perception of benefits and barriers of physical activity, respectively.

The self-rated ability for physical activity was assessed using exercise subscale of SRAHP. ${ }^{1}$ The scale had excellent internal consistency $(\alpha=0.765)$. The total score was analyzed; the higher the scores, the higher the self-rated ability for physical activity. ${ }^{14,15}$

The physical activity-related effect was measured using PAAS. ${ }^{16}$ It had minimally acceptable internal consistency $(\alpha=0.645)$. It consists of 12 items representative of 4 components, namely, positive affect, negative affect, fatigue, and tranquillity. A study from had shown that PAAS could be used to examine the physical activity-related effect of both physically active and physically inactive people. ${ }^{3}$

Social influences were measured using the Physical Activity and Social Support Scale (PASSS). ${ }^{5,16,17}$ It had excellent internal consistency $(\alpha=0.795)$. It consists of 20 items, comprised of five forms of functional social influence, namely, emotional support, informational support, instrumental support, validation support, and companionship support.

\section{Data collection procedures}

After the students identified, they were approached by the research team. Identified students were informed regarding the study and required to sign a written consent form. A self-administered questionnaire that consists of sociodemographic characteristics and five predictors adapted from HPM, namely perceived benefit, perceived barrier, self-rated ability, activity-related affect, and social influences, were given to the consented students. All the data obtained were entered into SPSS version 22 (SPSS Inc., Chicago, IL, USA) and were kept confidential.

\section{Data analysis}

Univariate analysis was executed to depict the sociodemographic characteristics of respondents, to obtain the average score for each predictor and the proportion of the physically active and inactive respondents. Moreover, the Chi-square test was executed to examine the relationship between sociodemographic background and degree of physical activity. Furthermore, Hierarchical Binary Logistic Regression was executed to explore the relationship between sociodemographic background and predictors of physical activity, namely perceived benefit, perceived barrier, self-rated ability, social influences, and activity-related affect with the level of physical activity. A p-value of $<0.20$ was a cut-off point 
used to identify the independent variables entered in the multivariate analysis. The statistically significant adjusted Odd Ratios (OR) with $95 \%$ confidence intervals $(95 \% \mathrm{CI})$ were documented. Findings were considered statistically significant when the p-value was less than 0.05 .

\section{RESULTS}

The total number of respondents analyzed was 409 . Table 1 displays the sociodemographic background of the respondents. The undergraduate students involved in this study were the Year-1 to Year-3 from eight different faculties in UNIMAS, namely FMHS, FENG, FCSIT, FRST, FEB, FCSHD, FSSH, and FLC. More than two-thirds of the respondents were female $(69.4 \%)$. Almost half of the respondents were Malay (40.3\%), followed by others (21.3\%), Iban (18.3\%), Chinese (16.4\%), and Indian (3.7\%).

Table 2 shows the majority of the respondents were physically active $(74.1 \%)$. Among them, half were categorized as moderately active (52.6\%), and one-fifth were highly active (21.5\%).

Table 3 displays the degree of physical activity and the mean age of respondents. The mean age for physically active students was $21.30(\mathrm{SD}=1.13)$, while physically less active students was $22.04(\mathrm{SD}=1.39)$. The mean age for those moderately active was $21.23(\mathrm{SD}=1.05)$ whereas, for those highly active was $21.48(\mathrm{SD}=1.30)$.

Table 4 displays the relationship between the degree of physical activity and the sociodemographic background of respondents based on the analysis by the Chi-square test. There was a significant relationship between the year of study and gender with the degree of physical activity. The proportion of physically active students in Year-1 (80.8\%) and Year-2 (83.1\%) were more compared to Year-3 students $(49.5 \%)(\mathrm{p}<0.05)$. The proportion of physically active male $(83.2 \%)$ was more than female $(70.1 \%)(\mathrm{P}<0.05)$. However, there was no significant relationship between races with the degree of physical activity.

Table 5 displays the mean score for each predictor of physical activity. The mean score for the perceived benefits measured using the perceived benefit scale was $32.61(\mathrm{SD}=4.80)$, whereas the mean score for the perceived barrier measured using the perceived barrier scale was $19.44(\mathrm{SD}=5.13)$.

The mean score for self-rated ability scale, measured using SRAHP questionnaire, was 18.08 ( $\mathrm{SD}=4.87)$. The mean score for activity-related affect scale, measured using PAAS questionnaire, was 25.15 ( $\mathrm{SD}=5.11$ ). The mean score for the scale of the social influence, measured using PASSS questionnaire, was $16.48(\mathrm{SD}=5.35)$.

Table 6 illustrates data analyzed using hierarchical binary logistic regression to assess the impacts of the control variables (independent) on the degree of physical activity (dependent variable). The event (dependent variable) was more likely to happen when $\mathrm{OR}>1$ and the p-value $<0.05$ (significant value). In both models, age was less likely to predict physical activity $(\mathrm{OR}=0.483$ in Model $1 ; \mathrm{OR}=0.45$ in Model 2). Both models show that males were more prone to participate in physical activity than females by three times $(\mathrm{OR}=3.533$ in Model 1, $\mathrm{OR}=3.201$ in Model 2). Races were not significant in predicting physical activity $(\mathrm{OR}<1)$. The perceived benefit was significant $(\mathrm{p}=0.005)$ but less likely to predict physical activity $(\mathrm{OR}=1.128)$. The perceived barrier was also significant $(\mathrm{p}=0.025)$ but less likely to predict physical activity $(\mathrm{OR}=0.910)$. Self-rated ability was significant $(\mathrm{p}<0.001)$ and very likely to predict physical activity $(\mathrm{OR}=1.241)$. Both social support $(\mathrm{p}=0.532)$ and activityrelated affect $(\mathrm{p}=0.679)$ were not significant in predicting physical activities.

\section{DISCUSSION}

The purpose of the study was to determine the degree of physical activity among undergraduate students in UNIMAS. It had shown that the majority of the students were active (74.1\%), and only a small percentage of the students were less active $(25.9 \%)$. This outcome correlates with a study done by, ${ }^{18}$ whereby it stated that $41.4 \%$ of their respondents were physically less active and $58.6 \%$ were physically active. Similarly, Ganguly et al. reported a higher proportion of private medical college students of Eastern India were physically active (59.2\%) than non-active. ${ }^{19}$ Contrarily, the study by Nariya et al. among students of S.S. Agrawal Institute of Physiotherapy and Medical Care Education reported a higher proportion of students who were less active $(68 \%) .{ }^{20}$ Furthermore, the mean age for physically active and less active students was 21.30 years old and 22.04 years old, respectively, corresponds to a previous study by Rajappan et al. ${ }^{6}$ that concluded an aged 22 to 25 years old as the least physically active compared to the 18 to 21 years old. ${ }^{6,7,12}$ More male $(83.2 \%)$ were physically active compared to female $(70.1 \%)$, in contrast with a study conducted in the Pharmacy Faculty of Medical University, whereby it stated that more females involved with physical activity than males. ${ }^{15}$

In this study, races were not influenced by the degree of physical activity, in contrast with another study which stated that Indians (36.8\%) were most physically active, followed by Chinese (36.4\%), Malay (25.9\%) and others $(23.5 \%){ }^{6}$ Furthermore, this study aims to examine the relationship between predictors of physical activity, namely perceived benefit, perceived barrier, self-rated ability, activity-related affect, and social influences, with the degree of physical activity among undergraduate students in UNIMAS. Our study had shown that both perceived benefits and barriers had a 
significant association with the degree of physical activity, similar to another study that had shown that perceived benefit was more important than the perceived barrier in affecting the level of physical activity. The reason behind this is that the behaviour that is associated with positive evaluations tend to be repeated. ${ }^{21}$ However, our finding was in contrast with another study done by ${ }^{22}$ whereby it stated that perceived benefit perhaps not adequate to motive people to be physically active.

This study also found that the mean score of self-rated ability to perform physical activity scale among the undergraduate students in UNIMAS was high. It probably developed from mastery experiences, which they gain from interpretation and evaluation of the obtained result, thus building their selfbelief of competence. ${ }^{13}$ Moreover, our findings had shown a significant relationship between self-rated ability with the degree of physical activity. It corresponds with another study done by Goje et al. ${ }^{18}$ that showed those with the high self-rated ability $(66.7 \%)$ were more likely to be physically active, compared to those with the low self-rated ability (49.3\%). However, our study had failed to support the relationship between other predictors, such as activity-related effect, and social influences with the degree of physical activity. The finding was in contrast with other studies that had shown that social support plays a vital role in predicting physical activity. Dayi et al. ${ }^{10}$ stated that the presence of physically inactive family members contributed to an individual being physically inactive. Whereas Davis and Cohen stated that responses to social support are inconsistent as people differ from each other, and social support negatively affects an individual's participation in physical activity. ${ }^{9}$ The finding was opposed to another study that mentioned social support gives positive effects on an individual's participation in physical activity. ${ }^{14}$

\section{CONCLUSION}

In conclusion, the undergraduate students of UNIMAS were physically active, particularly Year 1 and Year 2 of the study compared to Year 3 . Aged 21 years old, and males were more physically active than other age and females. However, further analysis using Hierarchical Binary Logistic Regression had shown that age and races were not a significant predictor of physical activity. Additionally, males were found to be more prone to participate in physical activity than females by three times. The study also found that self-rated ability can predict individual participation in physical activity. In contrast, perceived benefits, perceived barriers, activity-related effect, and social influences cannot.

\section{ACKNOWLEDGMENTS}

Authors acknowledge the immense help received from the scholars whose articles are cited and included in references to this manuscript. The authors are also grateful to authors/ editors/ publishers of all those articles, journals, and books from where the literature for this article has been reviewed and discussed.

Conflict of Interest: The authors have no conflict of interests to proclaim.

Funding: This study was not funded.

Author's Contribution: The authors confirm contribution to the paper as follows: Beatrice Reen Anak Gilbert, Desmond Tong Min Hang, Sarah Prosper Anak Atang and Nurul Adilah Binti Mohamed Farid wrote the manuscript in consultation with Jeffery Anak Stephen and Rafidah Binti Elias, carried out data collection and performed the analysis. Jeffery Anak Stephen and Rafidah Binti Elias were involved in planning and supervised the work, conceived and design the analysis, reviewed the statistical analysis and aided in interpreting the results. All authors reviewed the results and approved the final version of the manuscript.

\section{REFERENCES}

1. Becker H, Stuifbergen A, Oh HS, Hall S. Self-rated abilities for health practices: A health self-efficacy measure. J Health Behav Edu Promo 1993;17(5):42-50.

2. Blair SN. Physical inactivity and cardiovascular disease risk in women: Exercise and cardiovascular disease risk in women: interaction with selected endocrine factors. Med Sci Sports Exerc 1996;28(1):9-10.

3. Carpenter LC, Tompkins SA, Schmiege SJ, Nilsson R, Bryan A. Affective response to physical activity: Testing for measurement invariance of the physical activity affect scale across active and non-active individuals. Meas Phys Educ Exerc Sci 2010;14(1):1-4.

4. Zakariah N, Zainuddin H, Ragunath P, Mustapha FI. Physical Inactivity among Health Staff: What Influences the Behaviour. Mala J Med Health Sci 2018;14(3):16-23.

5. Institute for Public Health. National Health and Morbidity Survey 2011 (NHMS 2011). Vol. II: Non-Communicable Diseases, Risk Factors \& Other Health Problems 2015.

6. Rajappan R, Selvaganapathy K, Liew L. Physical activity level among university students: a cross-sectional survey. Int J Physiother 2015;3(6):1336-1343.

7. Poh BK, Safiah MY, Tahir A, Siti Haslinda N, Siti Norazlin N, Norimah AK, et al. Physical Activity Pattern and Energy Expenditure of Malaysian Adults: Findings from the Malaysian Adult Nutrition Survey (MANS). Malays J Nutr. 2010;16(1):233-238.

8. Cheah YK. Influence of socio-demographic factors on physical activity participation in a sample of adults in Penang, Malaysia. Malays J Nutr 2011;17(3):153-156.

9. Davis A, Cohen E. The effects of social support on strenuous physical exercise. Adapt Human Behav Physiol 2018;4(2):171187.

10. Dayi A, Acikgoz A, Guvendi G, Bayrak L, Ersoy B, Gur C, Ozmen O. Determination of factors affecting physical activity status of university students on a health sciences campus. Med Sci Monit 2017;12(4):323-325.

11. Molanorouzi K, Khoo S, Morris T. Motives for adult participation in physical activity: type of activity, age, and gender. BMC Public Health 2015;15(1):66-68. 
12. Sigmundová D, Chmelík F, Sigmund E, Feltlová D, Frömel K. Physical activity in the lifestyle of Czech university students: Meeting health recommendations. Eur J Sport Sci 2013;13(6):744-750.

13. Doménech-Betoret F, Abellán-Roselló L, Gómez-Artiga A. Self-efficacy, satisfaction, and academic achievement: the mediator role of Students' expectancy-value beliefs. Front Psychol 2017;8:119-123.

14. Eskiler E, Küçükibis HF. Sources of Social Support in Physical Activity Participation: The Moderating Effect of Gender. Int J Pae Ent Sci 2019;6(3):80-88.

15. Grygiel-Górniak B, Tomczak A, Krulikowska N, Przysławski J, Seraszek-Jaros A, Kaczmarek E. Physical activity, nutritional status, and dietary habits of students of a medical university. Sport Sci Health 2016 ;12(2):261-267.

16. Lox CL, Jackson S, Tuholski SW, Wasley D, Treasure DC. Revisiting the measurement of exercise-induced feeling states: The Physical Activity Affect Scale (PAAS). Meas Phys Educ Exerc Sci 2000;4(2):79-95.
17. Magnan RE, Kwan BM, Bryan AD. Effects of current physical activity on affective response to exercise: Physical and socialcognitive mechanisms. Psychol Health 2013;28(4):418-433.

18. Goje M, Salmiah MS, Ahmad Azuhairi A, Jusoff K. Physical inactivity and its associated factors among university students. J Der Med Sci 2014;13(10):119-130.

19. Ganguly R, Patnaik L, Pattanaik S, Sahu T. Physical activity and dietary habits among mbbs students of a private medical college of Eastern India. Int J Curr Res Rev 2020;12(21):69-75.

20. Nariya D, Sangtani S, Shah P, Patel D. Evaluation of levels of physical activity among students of S. S. Agrawal Institute of Physiotherapy and Medical Care Education. Int J Curr Res Rev 2019;11(16):5-8.

21. Jekauc D, Brand R. How do emotions and feelings regulate physical activity? Front Psychol 2017;8(4):114-115.

22. Lovell GP, El Ansari W, Parker JK. Perceived exercise benefits and barriers of non-exercising female university students in the United Kingdom. Int J Environ Res Public Health 2010;7(3):784-798.

Table 1: Sociodemographic characteristics of the respondents $(\mathrm{N}=409)$

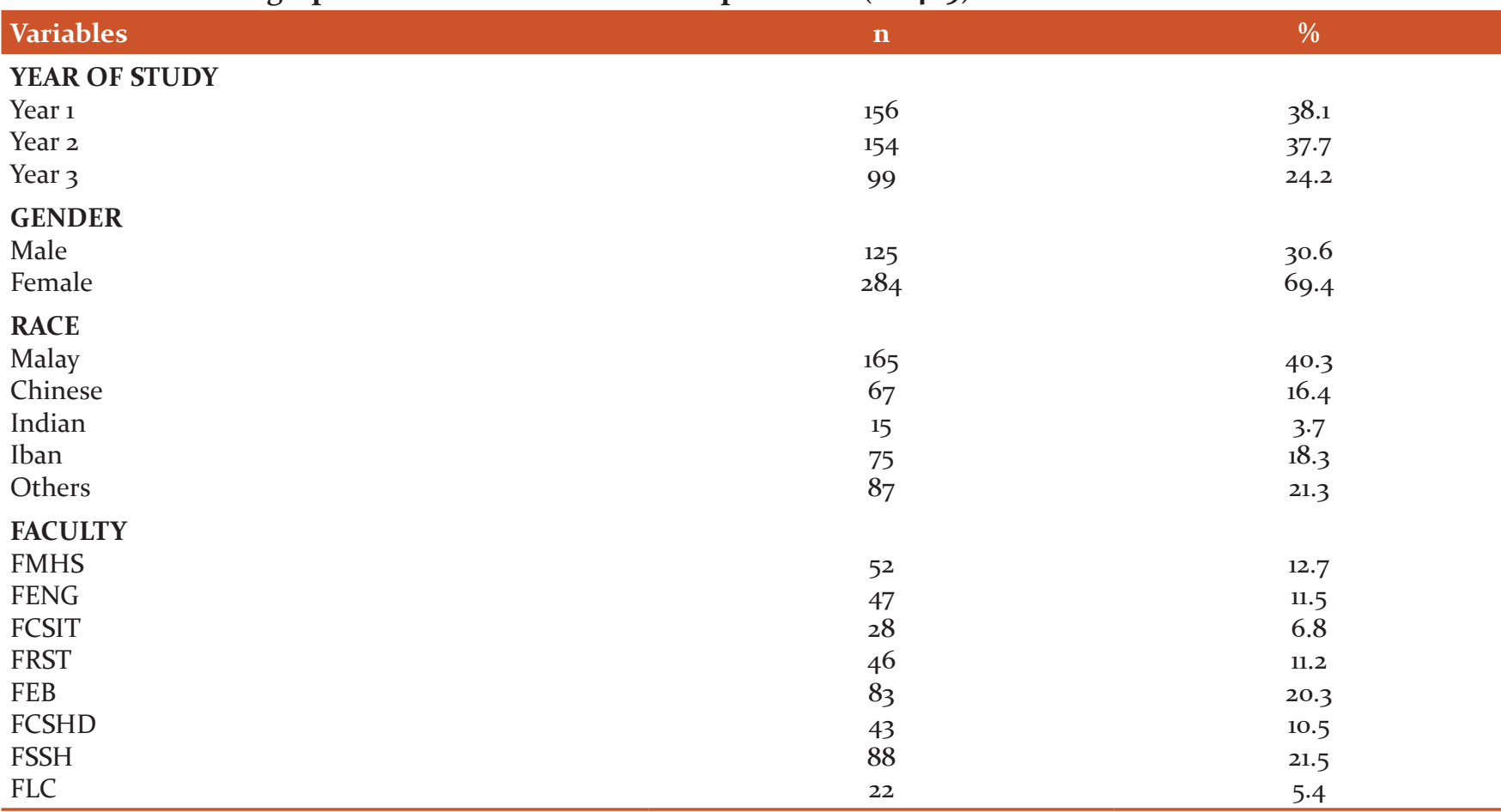

Table 2: Degree of physical activity among respondents $(\mathrm{N}=409)$

\begin{tabular}{lcc} 
Variables & $\mathbf{n}$ & $\%$ \\
DEGREE OF PHYSICAL ACTIVITY & & 25.9 \\
Sedentary & 106 & 52.6 \\
Moderately Active & 215 & 21.5 \\
Highly Active & 88 & \\
CATEGORY OF PHYSICAL ACTIVITY & & 25.9 \\
Less Active & 106 & 74.1 \\
Active & 303 & \\
\hline
\end{tabular}


Table 3: Degree of physical activity and age of the respondents $(\mathrm{N}=409)$

\begin{tabular}{lcc} 
& AGE & SD \\
Variables & Mean & \\
LEVEL OF PHYSICAL ACTIVITY & & 1.39 \\
Sedentary & 22.04 & 1.05 \\
Moderately Active & 21.23 & 1.30 \\
Highly Active & 21.48 & \\
CATEGORY OF PHYSICAL ACTIVITY & & 1.39 \\
Less Active & 22.04 & 1.13 \\
Active & 21.30 & \\
\hline
\end{tabular}

Table 4: Degree of physical activity and year of study, gender and race of the respondents $(\mathrm{N}=409)$

\begin{tabular}{|c|c|c|c|c|c|c|c|c|}
\hline \multirow{3}{*}{ Demographic } & \multicolumn{4}{|c|}{ Degree of Physical Activity } & \multicolumn{2}{|c|}{ Total } & \multirow{3}{*}{$x^{2}$} & \multirow{3}{*}{ p-value } \\
\hline & \multicolumn{2}{|c|}{ Less Active } & \multicolumn{2}{|c|}{ Active } & & & & \\
\hline & $\mathbf{N}$ & $\%$ & $\mathbf{N}$ & $\%$ & $\mathbf{N}$ & $\%$ & & \\
\hline YEAR OF STUDY & & & & & & & 41.351 & $0.000^{*}$ \\
\hline Year 1 & 30 & 19.2 & 126 & 80.8 & 156 & 100 & & \\
\hline Year 2 & 26 & 16.9 & 128 & 83.1 & 154 & 100 & & \\
\hline Year 3 & 50 & 50.5 & 49 & $49 \cdot 5$ & 99 & 100 & & \\
\hline GENDER & & & & & & & 7.793 & $0.005^{*}$ \\
\hline Male & 21 & 16.8 & 104 & 83.2 & 125 & 100 & & \\
\hline Female & 85 & 29.9 & 199 & 70.1 & 284 & 100 & & \\
\hline RACE & & & & & & & 8.176 & 0.085 \\
\hline Malay & 40 & 24.2 & 125 & 75.8 & 165 & 100 & & \\
\hline Chinese & 26 & 38.8 & 41 & 61.2 & 67 & 100 & & \\
\hline Indian & 3 & 20 & 12 & 80 & 15 & 100 & & \\
\hline Iban & 20 & 26.7 & 55 & 73.3 & 75 & 100 & & \\
\hline Others & 17 & 19.5 & 70 & 80.5 & 87 & 100 & & \\
\hline
\end{tabular}

${ }^{*} \mathrm{p}<0.05$ : significant

Table 5: Mean score for each predictor of physical activity $(\mathrm{N}=366)$

\begin{tabular}{lcccc} 
Variables & No. of items & Mean & SD & $\alpha$ \\
Perceived Benefits & 10 & 32.61 & 4.80 & 0.894 \\
Perceived Barriers & 10 & 19.44 & 5.13 & 0.856 \\
Self-Rated Ability & 7 & 18.08 & 4.87 & 0.765 \\
Activity-Related Affect & 12 & 25.75 & 5.11 & 0.645 \\
Social Influences & 10 & 16.48 & 5.35 & 0.795 \\
\hline
\end{tabular}

Table 6: Hierarchical Logistic Regression Analysis Predicting Degree of Physical Activity ( $N=352)$

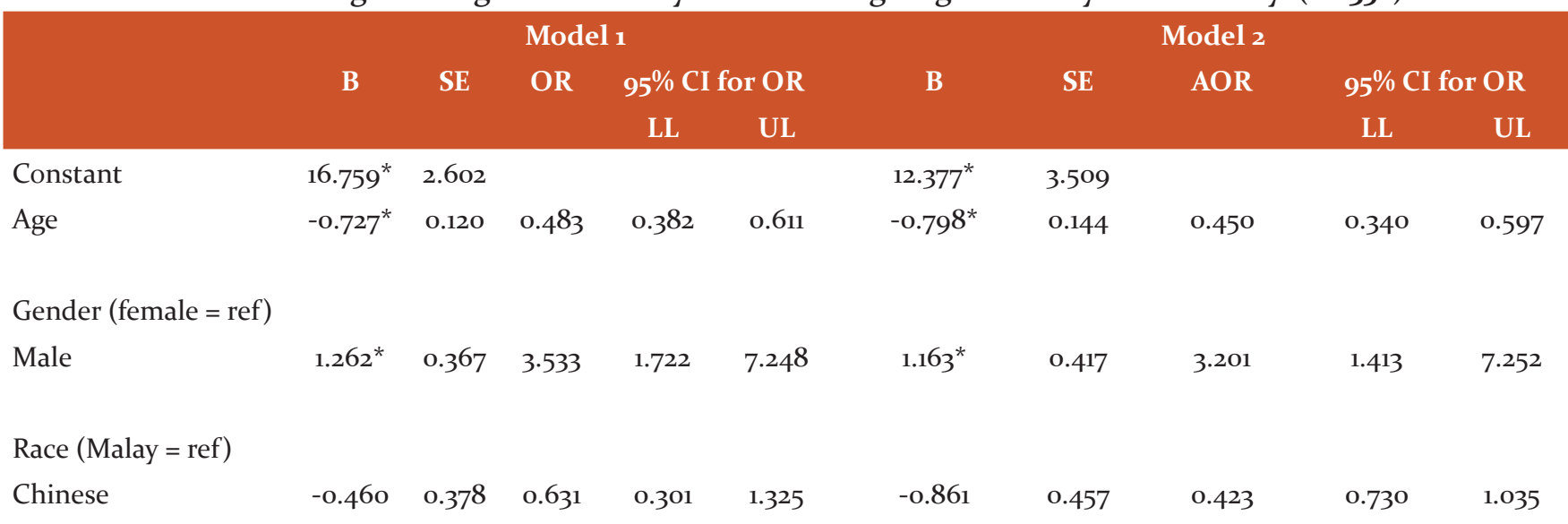


Table 6: (Continued)

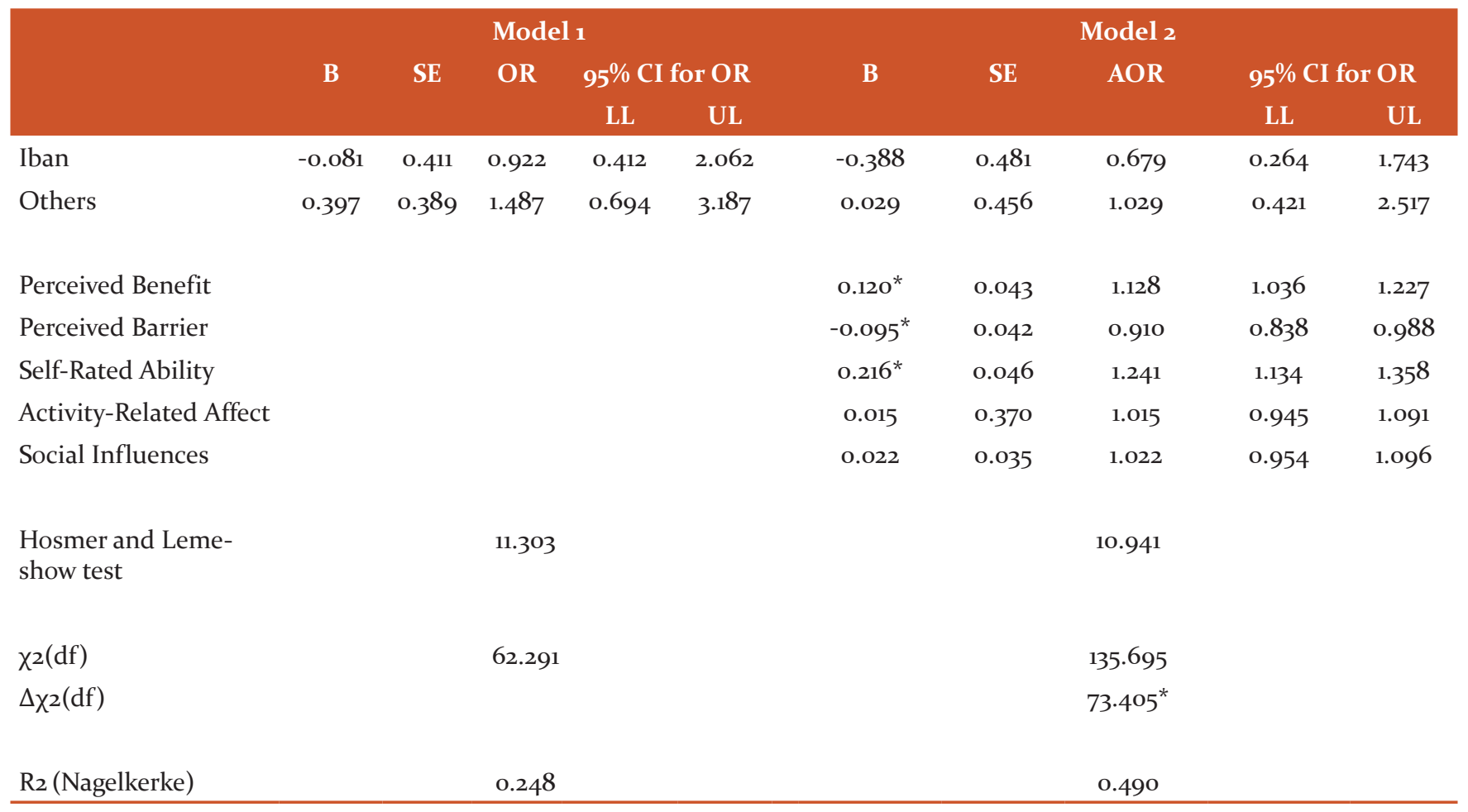

${ }^{*} \mathrm{p}<0.05$ 